\title{
Design of 500kJ Pulsed Power Supply System for Electromagnetic Rail Gun using PSPICE Simulation
}

\author{
R. Murugan ${ }^{1 *}$, S. Poorani ${ }^{2}$, Asghar Keshtkar ${ }^{3}$ and Leila Gharib ${ }^{3}$ \\ 'Department of Electrical and Electronics Engineering, Easwari Engneering College, \\ Chennai -600089, India; ramumurugan_r@rediffmail.com \\ ${ }^{2}$ Department of Electronics and Instrumentation Engineering, \\ Erode Sengunthar Engineering College, Erode - 638057, India \\ ${ }^{3}$ Electrical Engineering, Imam Khomeini International University IKIU, \\ Qazvin - 34149-16818, Iran; akeshtkar@gmail.com
}

\begin{abstract}
Pulsed power supply system plays an important role in rail gun system as it gives an electrical energy to rail gun in order to accelerate the projectile with higher velocity. Nowadays the pulsed power supply system which feed the rail launcher is still large and it is important to think about the minimization of the stored energy. The pulsed power supply system that has well enough small mass and volume, yet can offer properly conditioned power, is a vital component for the successful accomplishment of rail gun system. All embracing works and researches are being carried out all over the world for the minimization of the volume occupied by the power supply and its weight. Capacitor based pulsed power supply systems are the most familiar form of pulsed power supplies system used in rail gun research for the past several years. The design of a 500kJ capacitor module pulsed power system, which can able to accelerate the projectile with a velocity of $1 \mathrm{~km} / \mathrm{s}$ to $1.5 \mathrm{~km} / \mathrm{s}$, to be applied for the electromagnetic rail gun currently under investigation in India for surface fire support. In this paper an attempt is made to design a 500kJ PPS using computer simulation packages called PSPICE software in order to calculate the rail gun parameters such as acceleration of the projectile, muzzle velocity, peak current, current at exit, effective barrel length. Finally, this work gives some fundamental contemplation on volume and weight requirements of 500kJ capacitive PPS systems to be applied for speedy fire of electromagnetic rail guns.
\end{abstract}

\section{Introduction}

The encroachments of technology in the field of current weaponisation make use of the electrical energy as an imperative tool. Electromagnetic rail gun systems are such one which accelerates the projectile to greater velocities. The rail gun is a device which converts the electrical energy, which is supplied by pulsed power supply system, into mechanical energy for accelerating the projectile to hypervelocity. The Figure 1 shows the essential components of an electromagnetic pulsed power system. The Pulsed Power Supply (PPS) plays an imperative task in electromagnetic launcher system. The

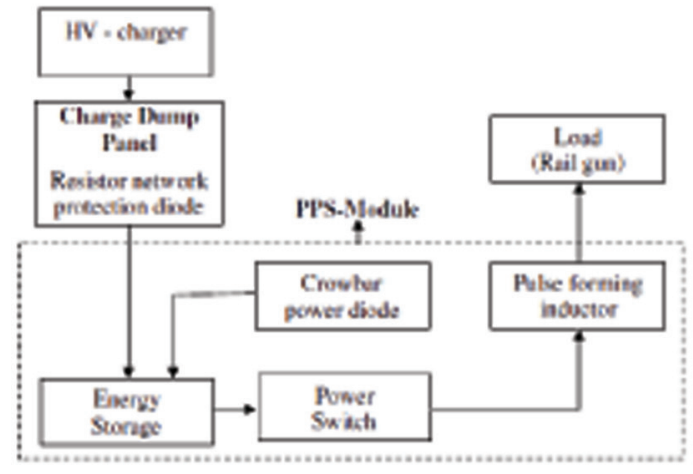

Figure 1. Simple schematic diagram of capacitor based pulsed power supply ${ }^{1}$.

${ }^{*}$ Author for correspondence 
PPS, which are commonly capacitor based and switched by semiconductor devices, is made up of modules called Pulse Forming Units (PFUs). These PFUs are assembled into a number of sections, and the modules in the same sections are switched concurrently ${ }^{2}$. In order to limit the peak current value in the bore and armature and reduce the electromagnetic force in the construction, in many cases, the total discharge current waveform of the PFN need be corrected to like rectangle wave shape ${ }^{3}$. Succession discharge in PFN is a one of the efficient way to get the similar rectangle current waveform. Achieving the constant level pulse is depends on the values of $\mathrm{L}, \mathrm{C}$, and the delay between pulses. It is possible to shape the pulse by implementing a non-uniform capacitance and inductance distribution among banks ${ }^{4}$. For the past several years a lot of work has been carried out on research and development of PPS based on a Pulse Forming Network (PFN). Many researchers have reported their work on simulation models and real model previously ${ }^{5-8}$. In this paper an attempt is made to design a 500kJ PPS which can be accelerate the projectile with a velocity of $1 \mathrm{~km} / \mathrm{s}$ to $1.5 \mathrm{~km} / \mathrm{s}$ using computer simulation packages called PSPICE software in order to calculate the rail gun parameters such as muzzle velocity, current at exit, effective barrel length. In order to identify better solution in this work different types of capacitors are grouped into different stages and then by varying the firing time of capacitor bank for each connection muzzle velocity, muzzle current, and effective barrel length are calculated. These values are then used to estimate the size of the capacitor banks and system inductances.

\section{Design of 500kJ Pulsed Power Supply using PSPICE Simulation}

Figure 2 shows the capacitor bank pulsed power supply with Electromagnetic rail gun load. The system has been mainly split into three parts namely an energy storage unit, rail unit and projectile unit. The energy storage unit consists of a capacitor followed by spark gap. The spark gap switch is replicated by the series amalgamation of a switch, a diode, and an on-state resistance. The crowbar diode is represented by a diode and an effective forward resistance. The pulse shaping inductor is modeled as an inductance and a related conductor resistance and the output cable is represented by its inductance and resistance. The inductance and resistance of the rails are varies linearly with respect to projectile position ${ }^{9}$.

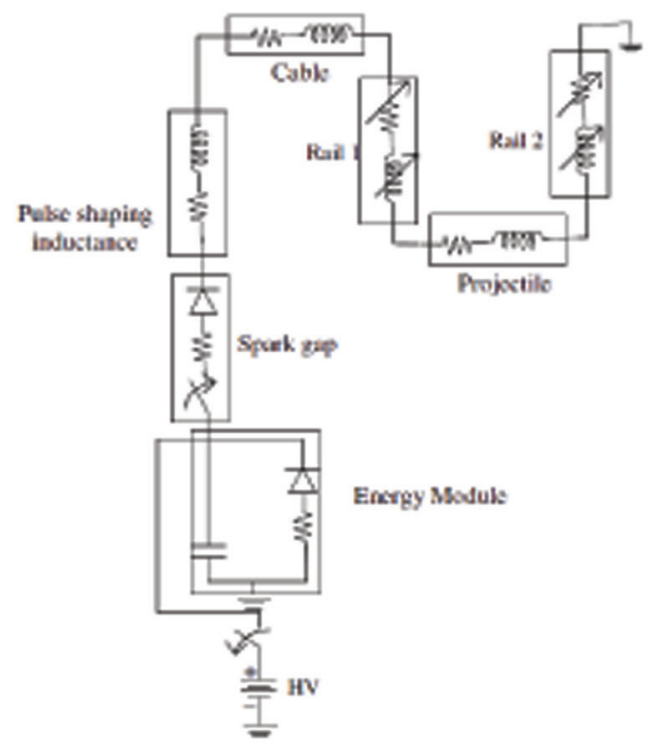

Figure 2. Capacitor bank Pulsed power supply system with rail gun load.

Table 1. Component used in pulsed power supply system with rail gun load

\begin{tabular}{|c|c|c|}
\hline S.No & Component & Value \\
\hline 1 & Capacitor ${ }^{10}$ & $2.3685 \mathrm{mf}$ \\
\hline 2. & Inductor & $\begin{array}{c}\text { Varies with respect with } \\
\text { respect }\end{array}$ \\
\hline 3 & Spark gap ${ }^{11}$ & $\begin{array}{l}\text { Operating Voltage }=50 \mathrm{kV} \\
\text { Peak Current }=500 \mathrm{kA}^{*}\end{array}$ \\
\hline 4 & Diode $^{12}$ & $\begin{array}{l}\text { Rep. Peak Reverse Voltage } \\
\text { \& Current VRRM }=6000 \mathrm{~V} \\
; \text { IRRM }=100 \mathrm{~mA}\end{array}$ \\
\hline 5 & Fuse $^{10}$ & $\begin{array}{c}\text { Rated pulse current } 6000 \mathrm{~A}, \\
\text { Voltage } 22 \mathrm{kV}\end{array}$ \\
\hline 6 & L' of the rail & $1.096 \mu \mathrm{H} / \mathrm{m}$ \\
\hline 7 & Mass of the projectile & rams \\
\hline
\end{tabular}

The capacitor bank and rail gun transient performance was simulated using PSPICE an electrical circuit analysis software package. Table 1 shows the components used to $500 \mathrm{~kJ}$ pulsed power supply with rail gun load.

\section{Simulation Results}

The circuit model, shown in Figure 3, simulates the circuits of the five module capacitor bank, and also solves the equations of motion for the projectile. The ZX element shown in Figure 3 allows the modeling of the timevarying rail inductance and resistance, which are dependent on projectile location in the barrel' ${ }^{9}$. 


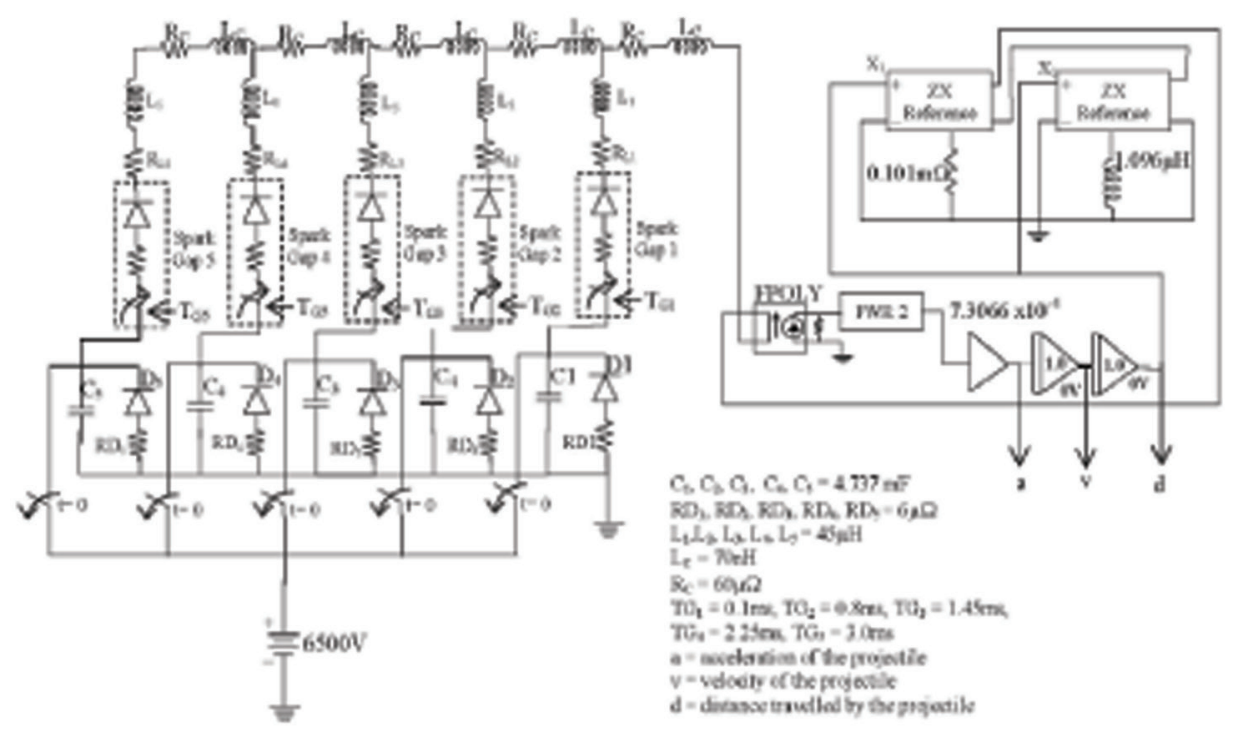

Figure 3. Five stage capacitor bank pulsed power supply system with rail gun load.

The equations of motion for the projectile in the barrel are solved by defining a separate series circuit that consists of a user-defined current controlled current source and two electronic integrators. The source current is defined by the rail gun acceleration equation ${ }^{5}$.

$$
a=\frac{1}{2 m} I^{2} L \mathrm{~m} / \mathrm{s}^{2}
$$

Where: I is the current delivered to load.

$\mathrm{m}$ is the mass of the projectile.

L' inductance gradient of the rails.

Velocity of projectile is obtained by integrating the acceleration and given as

$$
v=\int a d t \mathrm{~m} / \mathrm{s}
$$

The distance traveled by the projectile is obtained by integrating the velocity and given as

$$
d=\int v d t \mathrm{~m}
$$

In order to calculate the rail gun parameters such as acceleration, velocity, and distance traveled by the projectile using simulation, the total current supplied to the rails has to be separated from the circuit without affecting the rail impedance values. The portion FPOLY block, shown in Figure 3 is used to separate the load current from the circuit to calculate the rail gun parameters without affecting the rail impedance values. The current obtained from the FPOLY block is squared and then multiplied by the gain to calculate the acceleration of the projectile based on equation (1) and then uses two integration $A B M$ blocks to calculate the velocity of the projectile and distance traveled by the projectile. Energy storage device used in simulation is capacitor of $2.3685 \mathrm{mf}$ and manufactured by GEAP. The energy stored by one capacitor is 50 - kJ. Totally 10 capacitors have been chosen and they are connected in different combination to form a capacitor bank. Each capacitor is rated for $30 \mathrm{kA}$ current, so the predicted maximum current delivered by an each combination of a capacitor bank to the rail gun load is 300kA. The capacitor is initially charged to $6500 \mathrm{~V}$. In order to get optimum number of capacitor stages for $500 \mathrm{~kJ}$ pulsed power supply, in this work the capacitors are grouped in to a different module. Capacitors are grouped into single, double, triple, and five module. Usually capacitor modules are switched on sequentially in order to get nearby constant current. Normally the capacitor banks will be fired at the peak current level of the previous bank first the same is followed to get desired wave current wave shape. To get the rated current of each module pulse shaping inductance value varied from $1 \mu \mathrm{H}$ onwards and the output current is checked. Figure 4 shows the performance of single capacitor bank module.

In single capacitor bank module all the capacitors are connected in parallel and all are having same rating, hence all capacitors are delivered equal current. In the Figure 4(a) it is observed that the maximum current delivered to the load is obtained from simulation is 270 $\mathrm{kA}$, which is less than its rated value. From the figure it is also observed that exit current is equal to at $1.5 \mathrm{~ms} 10 \mathrm{kA}$. This current is called exit current in which projectile 


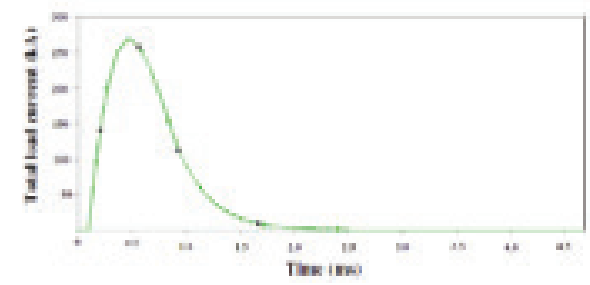

(a)

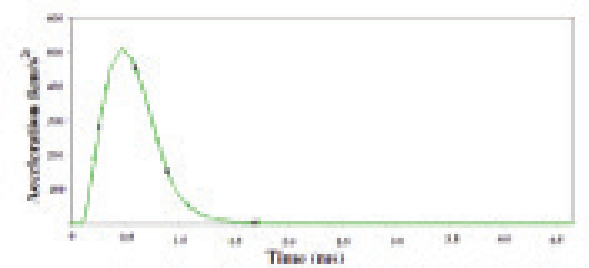

(b)

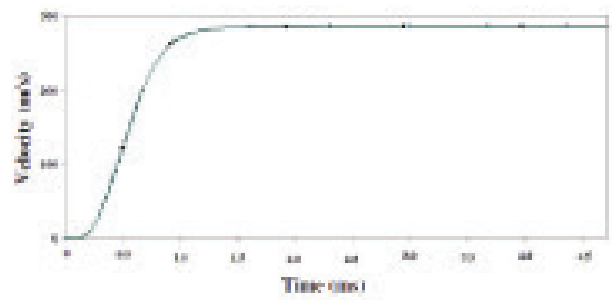

(c)

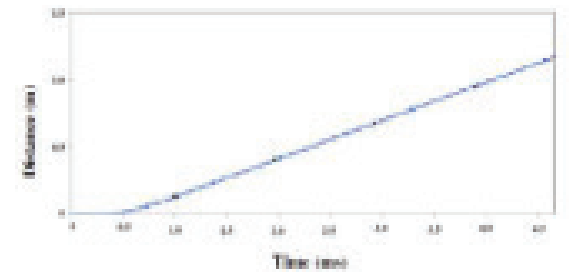

(d)

Figure 4. Performance of single stage capacitor bank module.

getting into space from rail. Figure $4(\mathrm{~b})$ it is observed that the peak acceleration of projectile is $280 \mathrm{~km} / \mathrm{sec}^{2}$. Figure 4(c) shows the predicted velocity of the projectile obtained from simulation. It is observed that the velocity of the projectile is constant after the time period $1.5 \mathrm{~ms}$. Therefore, the projectile under frictionless condition would exist the rails at $1.5 \mathrm{~ms}$. This graph can be used to get muzzle velocity of the projectile. The point after which the projectile velocity is constant, called muzzle velocity of the projectile. It is observed that the muzzle velocity of the projectile is $275 \mathrm{~m} / \mathrm{sec}$ at $1.5 \mathrm{msec}$. Figure 4(d) shows the predicted distance traveled by the projectile obtained from simulation. The distance travelled by the projectile graph can be used to calculate the effective barrel length of the rail. The point at which acceleration stops is called the effective barrel length, since the projectile does not gain velocity after this point. It is observed that the effective barrel length of the rail is $0.3 \mathrm{~m}$ at $1.5 \mathrm{~ms}$.

Figure 5 shows the performance of five module capacitor bank obtained from simulation. In this PPS, the capacitors are divided into five different groups in which two capacitors are connected in parallel. Usually capacitor groups are switched on sequentially in order to get nearby constant current. Normally the capacitor banks will be fired at the peak current level of the previous bank. In this connection, the duration of current that is supplied to rail is assumed as $5 \mathrm{~ms}$. So in this connection the values of acceleration, velocity and effective barrel length of the rails are calculated at 5ms. Figure 5(a) shows the capacitor discharge characteristics of five module capacitor bank module.

Figure 5(b) shows the individual capacitor current obtained from the simulation. The expected maximum current from each capacitor bank is $60 \mathrm{kA}$, from the figure it is observed that the current delivered by each bank is less than maximum current. It is also observed that the peak current time period (time taken to reach peak current value) for each capacitor bank is $0.6 \mathrm{~ms}, 1.45 \mathrm{~ms}$, $2.15 \mathrm{~ms} 2.8 \mathrm{~ms}$ respectively. The first capacitor is fired at $0.1 \mathrm{~ms}$; the remaining capacitors are fired sequentially for above time periods. Figure 5(c) show the total current flowing through the load. From the figure it observed that the total current delivered to load is less than rated value (i.e. $300 \mathrm{kA}$ ) of capacitor bank. From the figure it is observed that the current at $5 \mathrm{~ms}$ is $132 \mathrm{kA}$. This current is called exit current in which projectile getting into space from rail. Figure 5(d) shows that acceleration of projectile obtained from simulation. Figure 5(e) shows that velocity of projectile obtained from simulation. It is observed that Muzzle velocity of projectile is $900 \mathrm{~m} / \mathrm{sec}$ at 5 m.sec. Figure 5(f) shows the displacement of the projectile obtained from simulation. It is observed that the distance traveled by the projectile at $45 \mathrm{~ms}$ is 1.8 . This distance is equal to length of the rail. For each capacitor bank connection, pulse shaping inductance value, peak current value, current at exit, muzzle velocity, peak acceleration, pulse width and effective barrel length of the rails are calculated and the values are given in Table 2. From the Table 2, it is observed that increasing the number of stages in a capacitor bank module causes an increase in value of pulse width time, muzzle velocity of projectile, the time at peak current value, effective barrel length of the rails, current at exist and decrease in value of peak current and peak acceleration. 


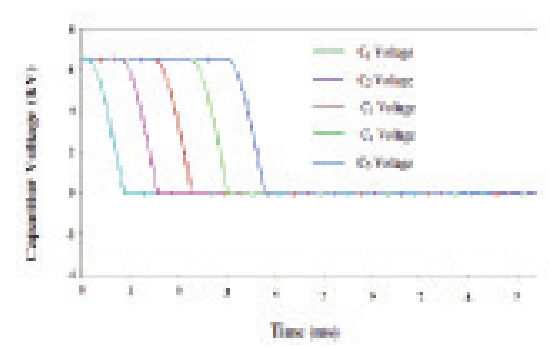

(a)

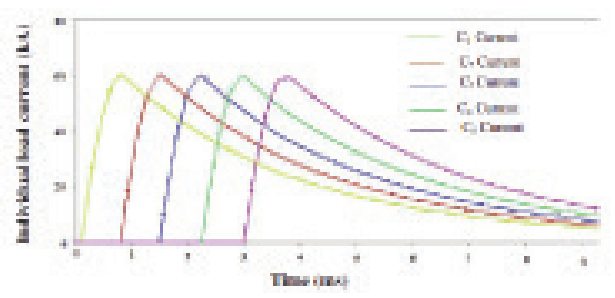

(b)

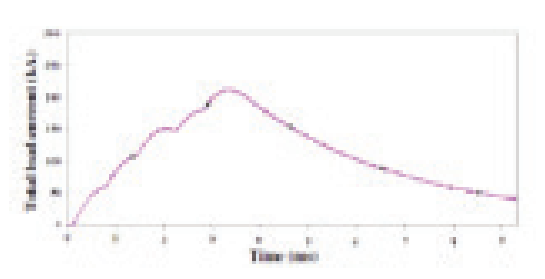

(c)

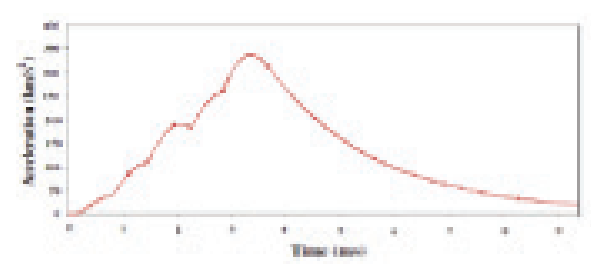

(d)

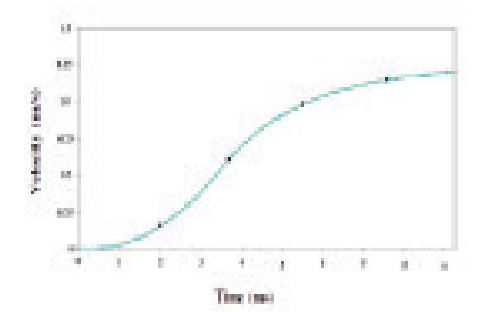

(e)

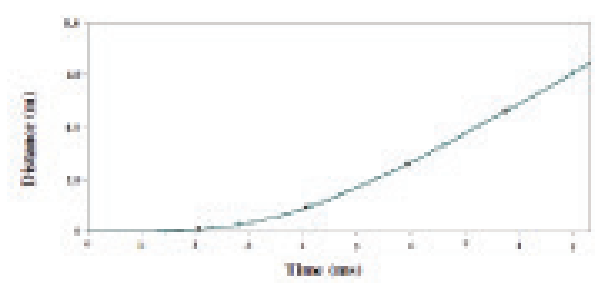

(f)

Figure 5. Performance of Five module capacitor bank.
From the Table 2 it is observed that by dividing the capacitor bank into five stages, it is able to get the projectile velocity of only $900 \mathrm{~m} / \mathrm{s}$. In order to improve the performance of 500kJ PPS the firing time of capacitor bank is changed. Two options have been taken to fire the capacitor bank sequentially.

Case 1. The capacitors are fired before the peak level of previous bank current.

Case 2. The capacitors are fired after the peak level of previous bank current.

For the above cases, peak current value, current at exit, muzzle velocity, peak acceleration, pulse width and effective barrel length of the rails are calculated and the values are given in Table 3 .

From the Table 3 it is observed that as the capacitor are fired before the peak level of previous bank

- The current delivered to the load, acceleration, velocity and projectile position are increased.

- The pulsed width is decreased.

It is also observed that as the capacitor are fired after the peak level of previous bank

- The peak current delivered to the load, acceleration, velocity and projectile position are decreased.

- The pulsed width and the current at exit are increased.

It is also been observed that that the 500kJ pulsed power supply can be able to accelerate a projectile at a velocity of $1.2 \mathrm{~km} / \mathrm{s}$, when the capacitor banks are fired before reaching peak level current of previous bank.

\section{Volume and Weight Calculation of $500 \mathrm{~kJ}$ Pulsed Power Supply}

The weight and volume occupied by $500 \mathrm{~kJ}$ is calculated and given Table 4 .

From the Table 4, it is observed that the 500kJ pulsed power supply needs $0.6686 \mathrm{~m} 3$ of volume with a total weight of $620 \mathrm{~kg}$. In the total weight of PPS calculation, the weights of the other components are not considered. The volume occupied by the inductor and its weight have been calculated using inductor calculator software. 
Table 2. Comparison of capacitor bank configurations

\begin{tabular}{|c|c|c|c|c|c|}
\hline \multirow[t]{2}{*}{ S. No. } & \multirow[t]{2}{*}{ Components } & \multicolumn{4}{|c|}{ No. of stages } \\
\hline & & 1 & 2 & 3 & 5 \\
\hline \multirow[t]{2}{*}{1} & Capacitor(mf) & $10 \times 2.3685$ & $1.5 \times 2.36852 .5 \times 2.3685$ & $\begin{array}{l}1.4 \times 2.3685 \\
2.4 \times 2.3685 \\
3.2 \times 2.3685\end{array}$ & $\begin{array}{c}\text { Each stage } \\
\text { has } 2 \\
\text { x2.3685 }\end{array}$ \\
\hline & $\begin{array}{l}\text { Energy stored } \\
\text { per bank }\end{array}$ & $500 \mathrm{~kJ}$ & $250 \mathrm{~kJ}$ per stage & $\begin{array}{l}1.200 \mathrm{~kJ} \\
2.200 \mathrm{~kJ} \\
3.100 \mathrm{~kJ}\end{array}$ & $\begin{array}{l}\text { 100kJ per } \\
\text { stage }\end{array}$ \\
\hline 2 & Inductor $(\mu \mathrm{H})$ & 5 & $\begin{array}{l}1.10 \\
2.10\end{array}$ & $\begin{array}{l}1.18 \\
2.18 \\
3.45\end{array}$ & 45 \\
\hline 3 & $\begin{array}{l}\text { Current pulse } \\
\text { width }(\mathrm{ms})\end{array}$ & 1.5 & 3 & 4 & 5 \\
\hline 4 & $\begin{array}{l}\text { Peak current } \\
\text { value }(\mathrm{kA})\end{array}$ & 270 & 240 & 220 & 214 \\
\hline 5 & $\begin{array}{l}\text { Time at } \\
\text { Peak current } \\
\text { value }(\mathrm{ms})\end{array}$ & 0.5 & 0.875 & 1.4 & 3.4 \\
\hline 6 & $\begin{array}{l}\text { Peak } \\
\text { acceleration }\end{array}$ & $\begin{array}{c}520 \mathrm{~km} / \\
\mathrm{sec}^{2}\end{array}$ & $420 \mathrm{~km} / \mathrm{sec}^{2}$ & $360 \mathrm{~km} / \mathrm{sec}^{2}$ & $\begin{array}{c}334 \mathrm{~km} / \\
\sec ^{2}\end{array}$ \\
\hline 7 & $\begin{array}{l}\text { Muzzle } \\
\text { velocity }\end{array}$ & $275 \mathrm{~m} / \mathrm{sec}$ & $370 \mathrm{~m} / \mathrm{sec}$ & $700 \mathrm{~m} / \mathrm{sec}$ & $900 \mathrm{~m} / \mathrm{s}$ \\
\hline 8 & Length of rail & $0.3 \mathrm{~m}$ & $0.8 \mathrm{~m}$ & $1.7 \mathrm{~m}$ & $1.8 \mathrm{~m}$ \\
\hline 9 & Exit current & $10 \mathrm{kA}$ & $77 \mathrm{kA}$ & $75 \mathrm{KA}$ & $142 \mathrm{kA}$ \\
\hline
\end{tabular}

Table 3. Comparison of five stage capacitor bank configuration with respect to firing time of capacitor bank module

\begin{tabular}{|c|c|c|c|}
\hline \multirow[t]{2}{*}{ Components } & \multicolumn{3}{|c|}{ Firing time of capacitor } \\
\hline & $\begin{array}{c}\text { Peak level of } \\
\text { previous bank }\end{array}$ & $\begin{array}{c}\text { Before the } \\
\text { Peak level of } \\
\text { previous bank }\end{array}$ & $\begin{array}{c}\text { After the } \\
\text { Peak level of } \\
\text { previous bank }\end{array}$ \\
\hline $\begin{array}{l}\text { Firing time of capacitor } \\
\text { bank (ms) }\end{array}$ & $\begin{array}{l}\text { Bank1 }=0.1 \\
\text { Bank2 }=0.8 \\
\text { Bank3 }=1.4 \\
\text { Bank4 }=2.2 \\
\text { Bank5 }=3.0\end{array}$ & $\begin{array}{c}\text { Bank1 }=0.1 \\
\text { Bank2 }=0.4 \\
\text { Bank3 }=0.6 \\
\text { Bank4=1 } \\
\text { Bank5 }=1.2\end{array}$ & $\begin{array}{c}\text { Bank1 }=0.1 \\
\text { Bank } 2=1 \\
\text { Bank3=1.65 } \\
\text { Bank4=2.45 } \\
\text { Bank5 }=3.2\end{array}$ \\
\hline Current pulse width & $5 \mathrm{~ms}$ & $4 \mathrm{~ms}$ & $5.5 \mathrm{~ms}$ \\
\hline Peak current value & $214 \mathrm{kA}$ & $263 \mathrm{kA}$ & $204 \mathrm{kA}$ \\
\hline $\begin{array}{l}\text { Time at Peak current } \\
\text { value }\end{array}$ & $3.2 \mathrm{~m} . \mathrm{sec}$ & $1.5 \mathrm{~m} . \mathrm{sec}$ & $4.6 \mathrm{~m} . \mathrm{sec}$ \\
\hline Peak acceleration & $334 \mathrm{k} \mathrm{m} / \mathrm{sec}^{2}$ & $492 \mathrm{k} \mathrm{m} / \mathrm{sec}^{2}$ & $320 \mathrm{k} \mathrm{m} / \mathrm{sec}^{2}$ \\
\hline Muzzle velocity & $900 \mathrm{~m} / \mathrm{s}$ & $1200 \mathrm{~m} / \mathrm{s}$ & $850 \mathrm{~m} / \mathrm{s}$ \\
\hline Length of rail & $1.8 \mathrm{~m}$ & $2 \mathrm{~m}$ & $1.5 \mathrm{~m}$ \\
\hline Exit current & $142 \mathrm{kA}$ & $112 \mathrm{kA}$ & $150 \mathrm{kA}$ \\
\hline
\end{tabular}


Table 4. Volume and weight calculation of $500 \mathrm{~kJ}$ pulsed power system

\begin{tabular}{lccc}
\hline $\begin{array}{l}\text { Component } \\
\text { Used }\end{array}$ & $\begin{array}{c}\text { No of } \\
\text { component }\end{array}$ & $\begin{array}{c}\text { Volume } \\
\text { occupied } \\
\text { m }^{3}\end{array}$ & Weight kg \\
\hline Capacitor & 10 & 0.169 & 300 \\
Fuse & 50 & 0.0035 & 100 \\
$\begin{array}{l}\text { Diode } \\
\text { Spark gap }\end{array}$ & 30 & 0.0285 & 60 \\
Inductance & 4 & 0.009 & 40 \\
$\begin{array}{l}\text { 20\% of total } \\
\text { volume allotted }\end{array}$ & & 0.0675 & 4 \\
for other & & 0.0573 & 20 \\
omponent & & & \\
Total & & 0.3276 & 524 \\
\hline
\end{tabular}

\section{Conclusion}

In this paper using PSPICE simulation packages the 500kJ pulsed power supply system that can be used in electromagnetic rail gun system has been designed. In PSPICE simulation, trade off study has been made to find the optimum number of capacitor stages to get desired current pulse shape and rail parameters. In order to identify optimum solution for 500-kJ PPS, capacitors have been grouped into single, double, triple and five stages. For each capacitor connection pulse shaping inductance value, peak current value, current at exit, muzzle velocity, peak acceleration value, pulse width, effective barrel length of the rails have been calculated. It has been observed that an increase in number of stages in a capacitor bank module causes an increase in value of pulse width time, muzzle velocity of projectile, the time at peak current value, effective barrel length of the rails, current at exit and decrease in value of peak current and peak acceleration. It has been concluded that the $500 \mathrm{~kJ}$ pulsed power supply can be able to accelerate a projectile at a velocity of $1.2 \mathrm{~km} / \mathrm{s}$, when the capacitor banks are fired before reaching peak level current of previous bank. The work has also been carried out to calculate the approximate weight and volume occupied by the pulsed power supply using the manufactured data's. It has been concluded that the $500 \mathrm{~kJ}$ pulsed power supply needed $0.6686 \mathrm{~m}^{3}$ of volume with a total weight of $620 \mathrm{~kg}$.

\section{References}

1. Wisken HG, Weise ThHGG. Critical components for high energy density capacitor modules. IEEE Trans. on Magnetics. 2003; 39(1):446-50.

2. Zhengjun S,Xinjie Y. Two-objective optimizationdesign for pulsed power supply. IEEE Trans. on Magnetics. 2009; 45(1):525-30.

3. Dai L, Wang Y, Zhang Q, Li W, Lu W, Dong H, Lin F. Effect of sequence discharge on components in a 600kJ PPS used for Electromagnetic Launch System. IEEE Transactions on Plasma Science. 2013; 41(5):1300-6.

4. Warnock SD. Design and optimization of a $600 \mathrm{~kJ}$ rail gun pulsed power supply[M.S. Thesis]. Monterey, California:Naval Postgraduate School; 2003, p. 26-7.

5. Bernardes SJ, Stumborg FM, Jean ET. Analysis of a capacitor-based pulsed-power system for driving longrange electromagnetic guns. IEEE Transaction on Magnetics. 2003; 39(1):486-90.

6. Tatake SG, Daniel KJ, Ghosh AA, Tokekar KP, Rao KR, Khan II. Modelling and simulation of a railgun powered by a capacitor Bank. Defence Science Journal. 1994; 44(2):131-7.

7. Hildenbrand DJ. Development and validation of the ARDEC army rail gun modular simulator (ARMS). IEEE Trans. Magns. 1993; 29(1):413-8.

8. Bernardes. Preliminary design of a $200 \mathrm{MJ}$ pulsed power system for a naval rail gun Proof of Concept Facility. EML. 2004p.409-94.

9. Wey J., Spahn E., Lichtenberger M. Rail gun modeling with the PSPICE code. IEEE Transaction on Magnetics. 1997; .

10. Available from: www.gaep.com

11. Available from: www.siliconpower.com

12. Available from: www.Titanpsd.com 